\title{
Rock physics attribute analysis for hydrocarbon prospectivity in the Eva field onshore Niger Delta Basin
}

\author{
Alexander Ogbamikhumi ${ }^{1} \cdot$ Nosa Samuel Igbinigie $^{1}$
}

Received: 1 April 2020 / Accepted: 5 August 2020 / Published online: 17 August 2020

(c) The Author(s) 2020

\begin{abstract}
Direct hydrocarbon indicator (DHI) expressions observed on seismic could arise due to various geological conditions. Such expression could lead to misinterpretation as hydrocarbon presence if not properly analyzed. This study employs rock physics attributes analysis to evaluate an identified prospect in the undrilled area of the studied reservoir. Prospect identification was actualized by analyzing structural and amplitude maps of the reservoir, which revealed a possible roll over anticline at both the exploited and prospective zone, with a very good amplitude support that conforms to structure. Well-based cross-plot analysis adopted four cross-plot techniques for feasibility study to test the applicability of rock physics for prospect evaluation in the field; Lambda-Rho versus Lambda-Rho/Mu-Rho ratio; Mu-Rho versus Lambda-Rho; and Poisson Ratio versus P-impedance. The result presented Poisson ratio, Lambda-Rho and Lambda/Mu-Rho ratio as good fluid indicator and Mu-Rho as a viable lithology indicator. As such, they were selected for seismic-based attribute and cross-plot analysis to validate the identified prospect. The results from seismic-based analysis showed consistency in the expression of the analyzed attribute at both the exploited and prospective zone. The seismic-based cross-plot analysis result was similar to the well-based analysis and was able to confirm that the observed amplitude expression in the exploited zone is an indication of hydrocarbon-bearing sand.
\end{abstract}

Keywords Rock attribute $\cdot$ Cross-plot $\cdot$ Seismic inversion $\cdot$ Prospect validation $\cdot$ Rock physics

\section{Introduction}

Seismic acoustic inversion and cross-plot analysis are effective tools in reservoir characterization. Avseth et al. (2008) define impedance inversion as a tool that offers insight into subsurface interpretation process, converting reflection amplitudes into more meaningful variations in layer properties (elastic properties), which can be related directly to the well $\log$ data after pertinent scale considerations has been made (Bosch et al. 2009). These established relationships are in turn incorporated to estimate rock attribute that can be employed to discriminate lithology and fluid for a typical field evaluation, especially in undrilled areas.

Rock properties are the physical properties of rocks that influence the propagation of seismic wave. They basically

Alexander Ogbamikhumi

alexander.ogbamikhumi@uniben.edu

Nosa Samuel Igbinigie

nosa.igbinigie@uniben.edu

1 Department of Geology, University of Benin, Benin City, Edo State, Nigeria include compressional wave velocity, shear wave velocity, density and their numerous derived attributes which include P-wave impedance, Poisson's ratio, S-wave impedance, etc. (Dewar and Pickford 2001). The observed amplitudes on seismic data are as a result of contrast or variation in these rock properties at the boundary between two geological or geophysical interfaces, i.e., changes in lithology or fluid in the subsurface (Brown 1987). Analysis of these amplitudes provide valuable information across field between and away from well control points, providing greater understanding of the subsurface geology heterogeneity related to lithology and fluid effect (Ogbamikhumi et al. 2017).

Advanced cross-plot is now a commonly used technique in rock physics analysis as it allows for a fast and more meaningful evaluation of attributes effortlessly (Castagna and Swan 1997). Generally, majority of the common lithology units and fluid types tend to form separate clusters in cross-plot space and this helps in making a direct interpretation (Omudu and Ebeniro 2005).

In the present study, rock physics and cross-plot analysis of inversion-derived elastic attributes were analyzed to validate an identify prospect in the prospective zone (the zone

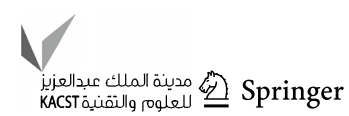


in the red ellipse of the semblance map in Fig. 1) of a major reservoir in the Eva field, Niger Delta Basin.

\section{Geology of Niger Delta and the study field}

The Niger Delta Basin is a tertiary delta located in the Gulf of Guinea (Fig. 1). The Niger delta is known to consist of three litho units (Fig. 2): an upper delta top litho facies, an intermediate delta front facies and a deeper pro-delta lithofacies (Short and Stauble 1967; Reijers et al. 1996). The typical sections of these formations are discussed by Short and Stauble (1967) and summarized in a number of papers (Avbovbo 1978; Doust and Omatsola 1990; Kulke 1995). Majority of the key hydrocarbon-bearing reservoirs in the delta exist within the Agbada Formation and are commonly situated in zones with structural heterogeneity. The formation consists mostly of channel and shoreface sands with slight shales in the upper part, and intercalation of shales and sands in equivalent ratio at the lower part of the basin Whiteman (1982).

Structurally, the basin is subdivided into overlapping structural depo-belts that get younger and structurally complex southward (Fig. 1). The depo-belts are typically defined by syn-sedimentary growth faulting and folds that trends east-west direction. The study field is situated in the Central Swamp depo-belt, and it is characterized by a major east-west trending faults at the north and several intra reservoir faults (Semblance map to the west of Fig. 1).

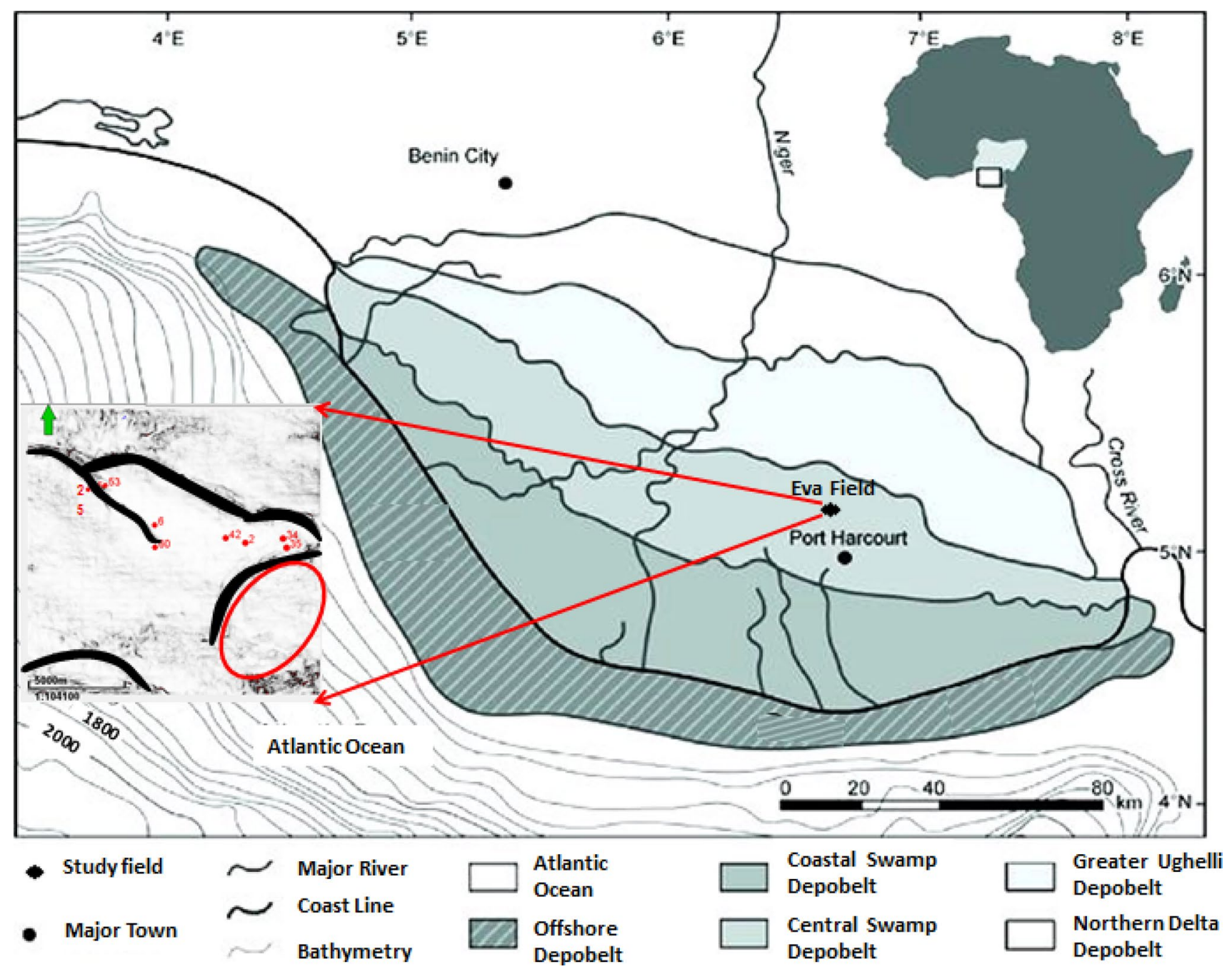

Fig. 1 Map of the Niger Delta Basin showing the various depo-belts, location of the prospective zone of the study Eva field (Modified after Adojoh et al. 2017) 


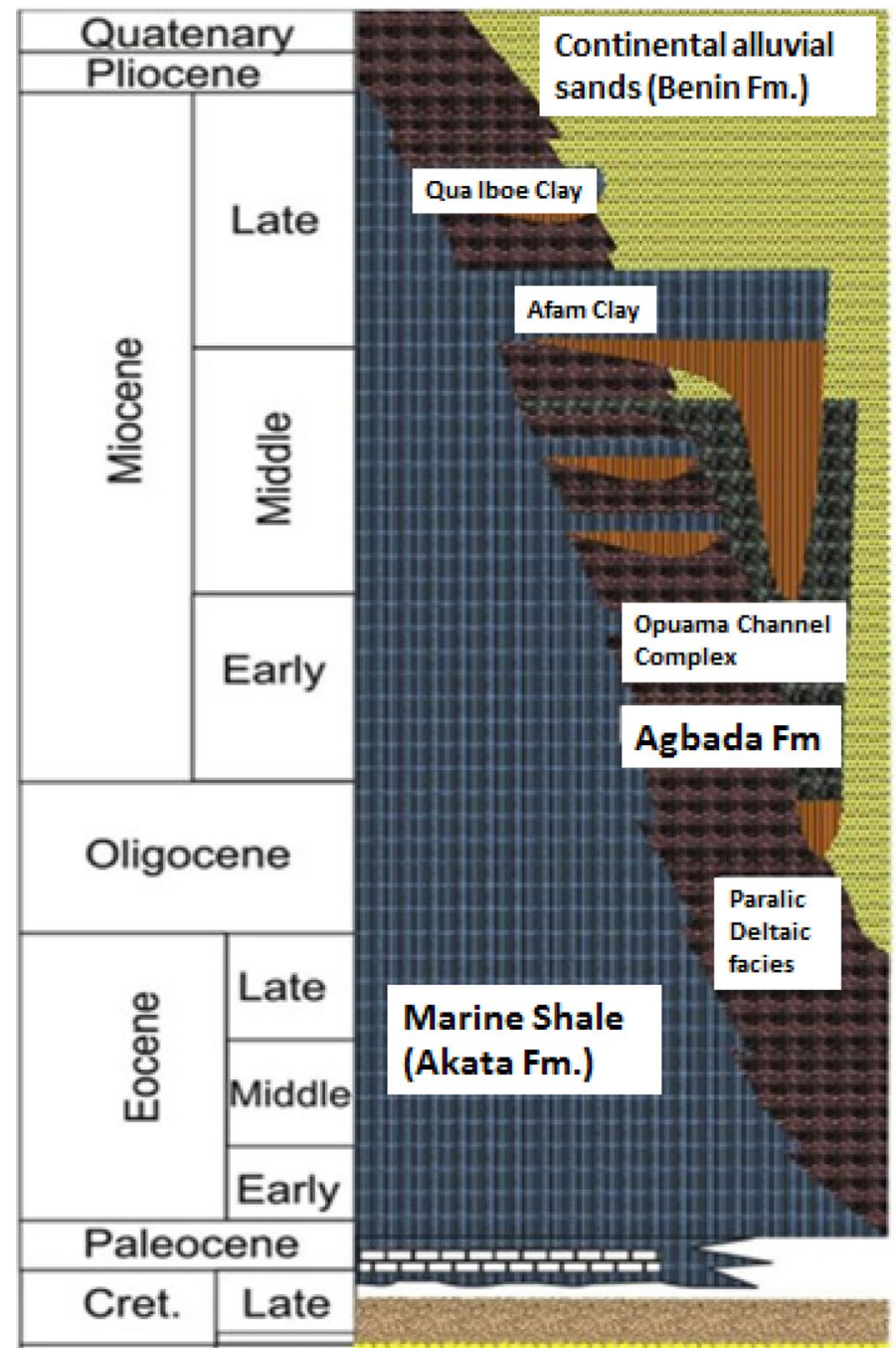

\section{Legend}

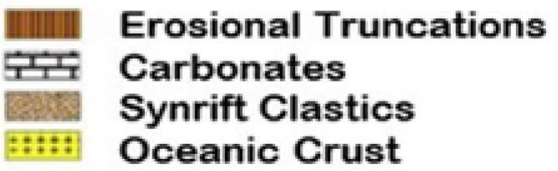

Fig. 2 Stratigraphic section of the Niger Delta, showing the three major formations (Modified after Doust and Omatsola 1990)

\section{Datasets and methodology}

A full stack 3D seismic data with dimension approximately 226 sq.km and eight wells were available for the study (Fig. 1). Generally, the qualities of the logs were good enough and suitable for this study.

Potential hydrocarbon prospect is defined if a reservoir is trapped within structural traps such as fault blocks or stratigraphic traps. Seismic expressions from similar traps have been analysed as hydrocarbon presence (Toshev 2017; Adeoti et al. 2018; Abdel-Fattah et al. 2020) Hence, Root Mean Square (RMS) amplitude was extracted from the seismic volumes on the interpreted surface of the prospective reservoir and compared with the structured map to identify the hydrocarbon prospect studied.

Post-stacked model-based inversion was conducted to extract elastic rock attribute for fluid presence detection from the seismic. Shear wave estimation for both the well-based cross-plot analysis and the inversion process was achieved using the Biot-Gassmann's fluid substitution theory, and Castagna's equation was sequentially adopted. The Biot-Gassmann's equations relate the bulk moduli of mineral matrix, the porous rock frame and the pore fluids (Gassmann 1951). The application of this equation is a twopart process, whereby we first determine the bulk modulus of the porous rock frame (the bulk modulus of the rock devoid of its initial pore fluid, also known as the "dry frame" bulk modulus), after which we calculate the bulk modulus of the rock saturated with brine (Smith et al. 2003). After which a modified form of the Castagna's equation for the Niger Delta Basin was employed to estimate shear wave for the field (Ogbamikhumi et al. 2019).

One of the advantages of the model-based inversion is that the very low-frequency end of the seismic data can be compensated for by low-frequency model built from well log data (Fig. 3). 


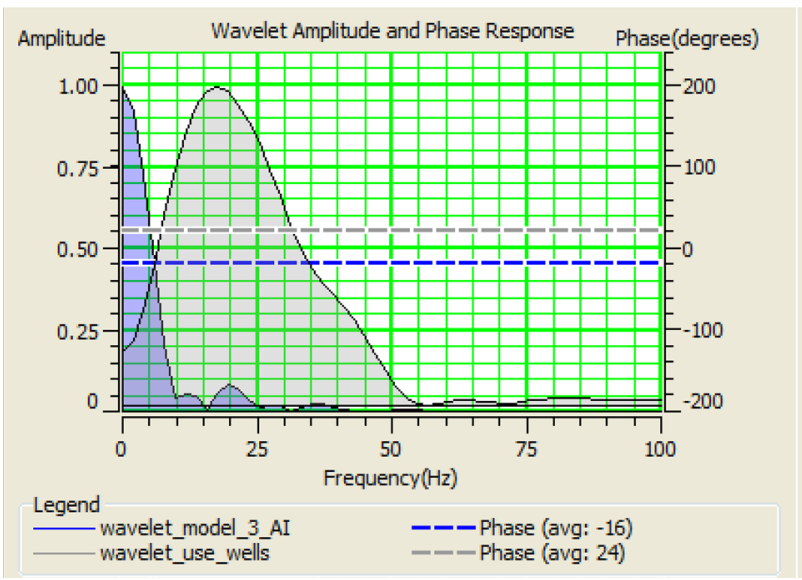

Fig. 3 Comparison of amplitude spectrum of wavelet extracted from the seismic data (light blue shade) and that extracted from the lowfrequency model built from well $\operatorname{logs}$ (dark blue shade) for modelbased inversion process to compensate for depleted low-frequency spectrum of the seismic data

Inversion analysis was conducted on the six wells with the complete suites of acoustic logs. An erroneously high impedance contrast was observed between the inverted $\log$ and the computed log from seismic for well 1 and 61 (Fig. 4). The observed errors in both wells could be as a result of severe wash out observed on the caliper logs at some depth intervals within the two wells, which might have compromised the integrity of the acoustic logs that were employed to compute the acoustic impedance logs. Hence, these two wells were excluded from the final inversion process. Also, the correlation of inversion and well-derived synthetic shows good correlation greater than $80 \%$ in most of the wells.

Well-based rock attribute cross-plot analysis was carried out to select suitable rock attributes and cross-plot templates to be adopted for seismic-based analysis. Pickett (1963) and Goodway et al. (1997) suggested four rock attributes derived from seismic inversion for lithology and pore fluid discrimination; Vp/Vs or Poisson ratio, Lambda modulus and density, Shear rigidity and density and P-wave Impedance. They demonstrated that the Lamé parameter terms $\lambda \rho$ (Lambdah Rho) and $\mu \rho$ (Mu-Rho) to be good pore fluid and lithology indicators, respectively. For clastic rocks, Li (2004) shows that $\lambda \rho$ reduces with an increasing porosity, increasing gas content and a decreasing shale content. Responses of the rock attribute to fluid and lithology changes adopted in this study for both well and seismic-based cross-plot analysis are summarized in Table 1.

\section{Results and discussion}

\section{Prospect identification}

Structural maps are time surfaces generated from interpreted horizon. Structural map of the prospective reservoir in Fig. 5 has six interpreted faults: one major fault to the north and five intra-reservoir faults. Both the exploited zone (zone with well penetrations) and the prospective zone (the area within the ellipse) are located at region with the least time values

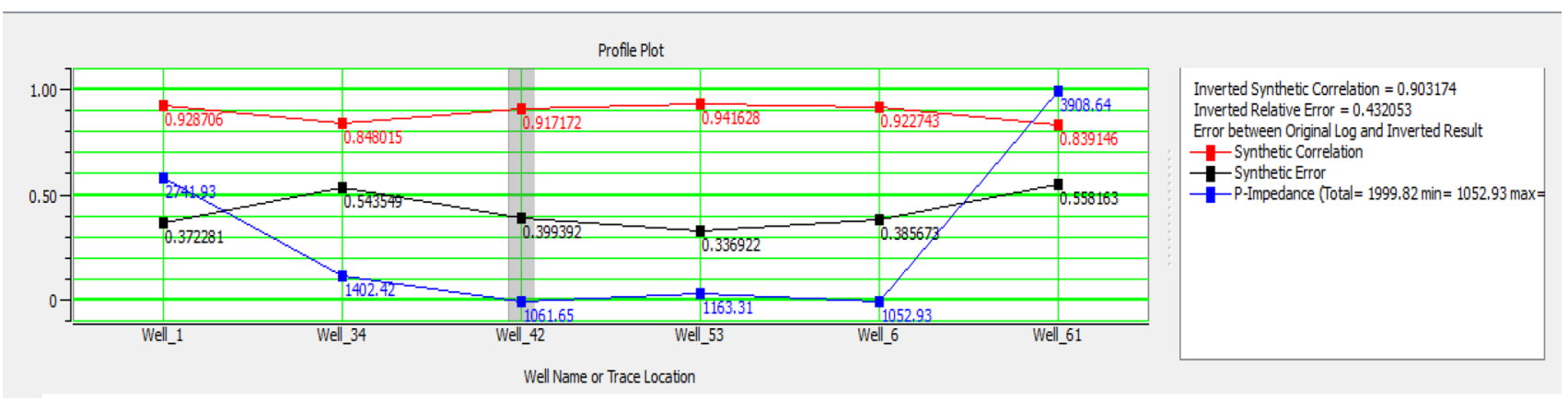

Fig. 4 Synthetic correlation, relative error and P-impedance error for the six wells available for inversion

Table 1 Summary of rock properties for lithology and fluid discrimination (Omudu and Ebeniro 2005)

\begin{tabular}{llllll}
\hline Lithology/fluid type & Mu-Rho & P-impedance & Lambda-Rho & Mu-Rho/Lambda-Rho & Poisson ratio \\
\hline $\begin{array}{l}\text { Shale } \\
\text { Brine sand }\end{array}$ & $\begin{array}{l}\text { Very low value } \\
\text { Hydrocarbon sand }\end{array}$ & $\begin{array}{l}\text { Very high value } \\
\text { Similar value to that of } \\
\text { brine sand }\end{array}$ & Very high value & Very high value & Very high value \\
& Lower than brine sand & Low value & Low value & Low value \\
& & & $\begin{array}{c}\text { Much more lower than brine sand } \\
\text { brine sand }\end{array}$ & Lower than brine sand \\
\hline
\end{tabular}



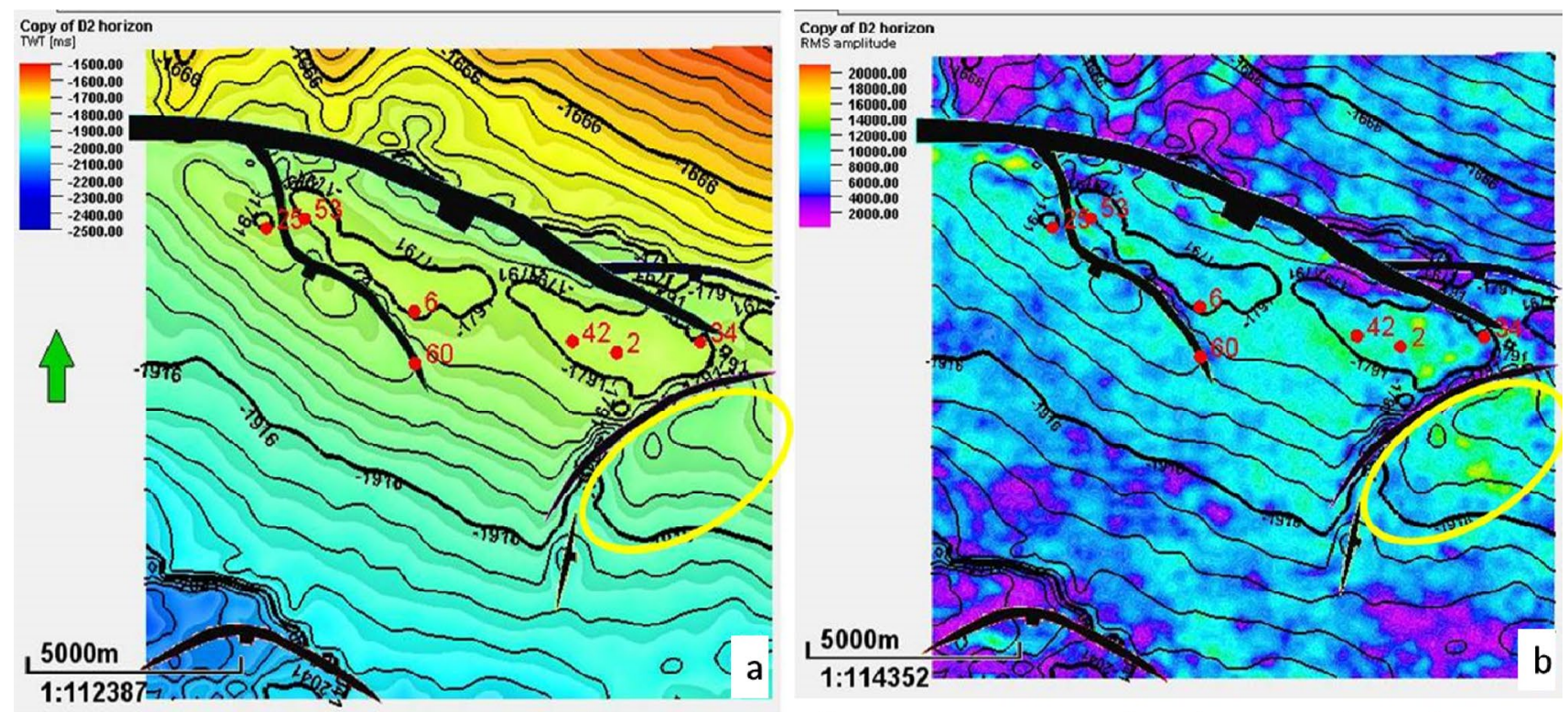

Fig. 5 a Structural map of D2 reservoir, b an overlay of amplitude map of D2 reservoir on the structural map for prospect identification

in the various structures that defines the zones. According to Asquith and Gibson (1982), a reservoir is considered to be a potential hydrocarbon prospect if it is enclosed within structural or stratigraphic traps. From the legend, the structural maps indicated that the region where the wells are concentrated is structurally high with the highest elevation, where hydrocarbon will most likely accumulate due to buoyancy effect. It is bounded at the north by the major synthetic faults and by several intra-reservoir faults at the south. At the prospective zone also, the legend shows that the zone is a structural high bounded by one of the intra-reservoir faults. Reservoirs in the field at this zone might be a good prospect as it is bounded by fault blocks which can aid the hydrocarbon trapping mechanism. The traps defined in the field are anticlinal which may or may not be fault supported.

Prospect identification also involves the observation made to identify seismic response that can be related to hydrocarbon presence commonly known as direct hydrocarbon indicator (DHI).

Amplitude extracted on structural maps points out with some level of certainty hydrocarbon prospect provided the amplitude response conforms to structure. Conformance to structure simply means encasement of the response within identified traps on the structured maps.

The D2 reservoir amplitude map in Fig. 5 shows bright amplitude at both the exploited and prospective zones. The accumulation in the exploited and prospective zones seems to rest on the encasing faults, typical of what is described as a fault-assisted accumulation. The map reveals a good amplitude expression that conforms to structure, with bright amplitude response within the exploited zone. The same bright amplitude was also observed within the prospective zone, defining a potential hydrocarbon prospect, which will be investigated further.

\section{Well-based rock physics cross-plot analysis}

Cross-plotting is a graphical representation of the plot of two or more rock properties. It aids easy and meaningful evaluation of these rock properties (Castagna and Swan 1997). The cross-plot techniques employed for the well-based analysis include: Mu-Rho versus Lambda-Rho cross-plot, the Lambda-Rho versus Lambda-Rho/Mu-Rho cross-plot and Poisson Ratio versus P-impedance cross-plot.

Resistivity log were used to color code the cross-plotted area to give an indication of the presence of hydrocarbon within the cross-plotted depth interval. A very high value of resistivity is an indication of the presence of a less conductive fluid than brine. Such high resistivity values are an indication of the presence of a more resistive media such as hydrocarbon, which could be partially or completely replacing brine in the reservoir.

\section{Mu-Rho versus Lambda-Rho cross-plot analysis}

$\mathrm{Mu}$ is an $\mathrm{S}$-wave-derived parameter known as rigidity. It is expected to have a value that is higher in sand than in shale since sand matrix exerts greater resistance to shearing than shale matrix will. Its value is not affected by the nature of fluid in the pore spaces; hence, the value for brine and hydrocarbon fill sand is expected to remain relatively constant. Therefore, for clastics, $\mu \rho$ which is its product

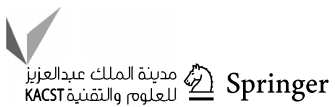


with bulk density is a good lithology indicator with high values indicative of sand (Goodway et al. 1997). LambdaRho on the other hand is a P-wave-derived parameter known as incompressibility. Since fluid contributes a reasonable amount to the total resistance exerted by a rock to compression, a change in fluid type and saturation is important in determining the incompressibility of a rock. A systematic change in fluid type from brine to oil then to gas will lead to significant gradual reduction in the incompressibility of a rock. Mu-Rho, its product with bulk density of the rock, is a good gas-sand indicator with a low value being consistent with gas sand.

Therefore, a cross-plot of these two parameters presented in Fig. 6, defined a zone with low Mu-Rho, high LambdaRho and low resistivity values that correspond to the base and top of the reservoir (as defined in the well log panel) typical of shale lithology (brown ellipse) and a second zone with high Mu-Rho and low Lambda-Rho value defined as brine sand (blue ellipse), and it corresponds also to the blueshaded zone in the well log panel. A third zone is defined with high Mu-Rho, very low Lambda-Rho and high resistivity value typical of a hydrocarbon-bearing sands corresponding to the red-shaded zone in the well log panel. In conclusion, Mu-Rho gave good separation between sand and shale along the horizontal axis and hence can serve as a good lithology discriminant in the study field on seismic. Likewise, the Lambda-Rho gave good separations along the horizontal axis between brine fill and hydrocarbon-filled reservoir. Hence, this cross-plot technique or template will be suitable for seismic-based cross-plot analysis in the undrilled area of the prospective reservoir.

\section{Lambda-Rho versus Lambda-Rho/Mu-Rho cross-plot analysis}

The ratio Lambda-Rho/Mu-Rho is a complex ratio that gives a high value for shale, lower value for brine sand and a much more lower value for hydrocarbon-bearing sands (Omudu and Ebeniro 2005). The cross-plot of Lambda-Rho against this ratio presented in Fig. 7 shows very high values for both lambda-Rho and the ratio of Lambda-Rho/Mu-Rho, defining shale lithology. Lower values of both parameters indicate brine sand, and a much lower value of both attributes corresponds to hydrocarbon sands. Thus, both parameters can be used to characterize lithology and fluid on seismic for prospect evaluation.

\section{Poisson ratio versus P-impedance cross-plot analysis}

Poisson ratio is a more advance averaging of the $\mathrm{Vp} / \mathrm{Vs}$ ratio that discriminates shale with a high value, from sand with a lower value. For mix hydrocarbon and brine reservoir, a much lower value will be observed for hydrocarbon-bearing sand as compared to brine sand. The ratio is a fluid indicator because $\mathrm{P}$-waves are sensitive to fluid changes, whereas S-waves are not (Han et al. 2007; Ujuanbi et al. 2008; Krebs et al. 2009; Ogararue and Anine 2016). Hence, a reduction is expected for a change in fluid content from brine to oil, or from oil to gas. P-impedance is a product of P-wave velocity and density. Since both P-wave and density respond similar to the presence of hydrocarbon with a reduction, a product of both will have a multiplier effect that is expected to differentiate hydrocarbon-bearing sand from brine-filled sand
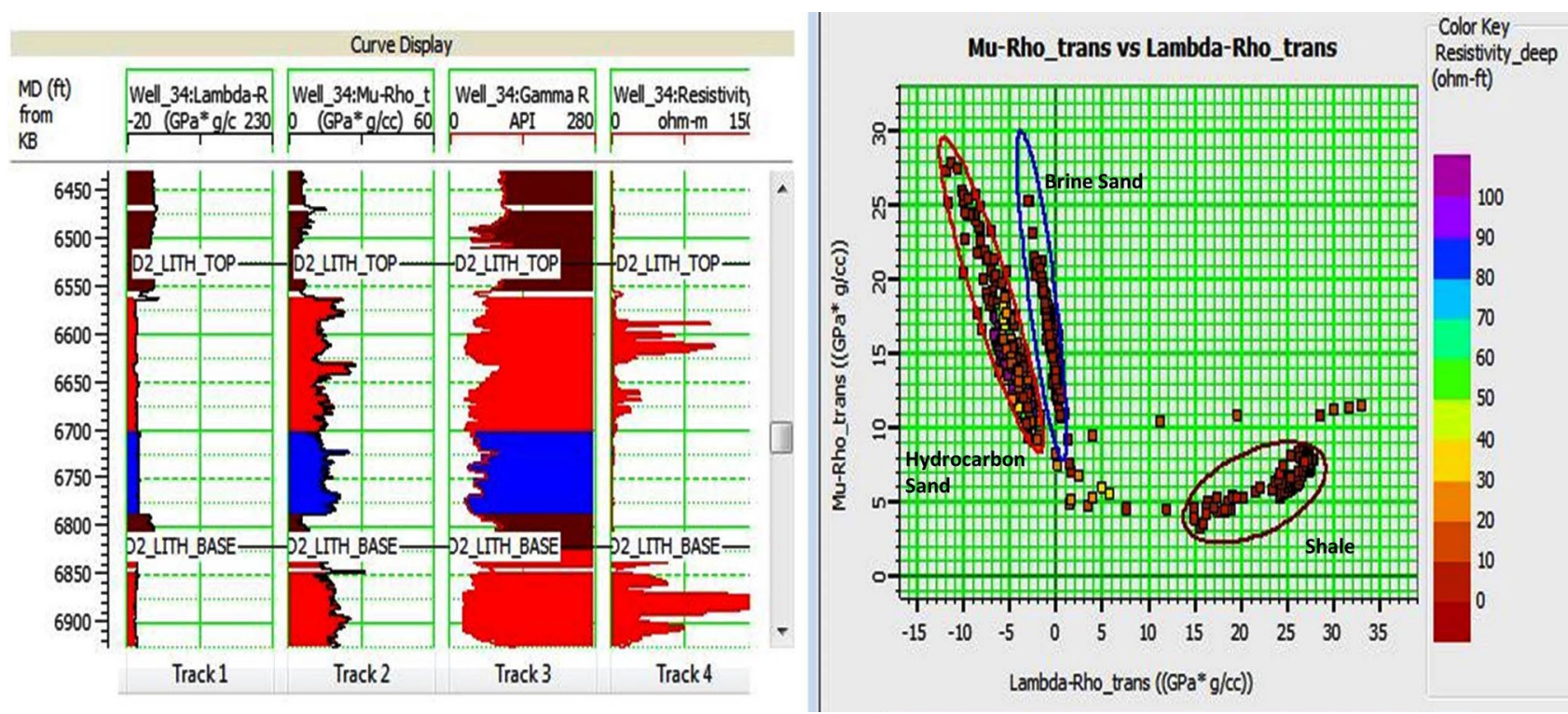

Fig. 6 Plot of Mu-Rho versus Lambda-Rho for C3 reservoir showing a good separation between sand and shale but a fair separation between brine and oil sand 

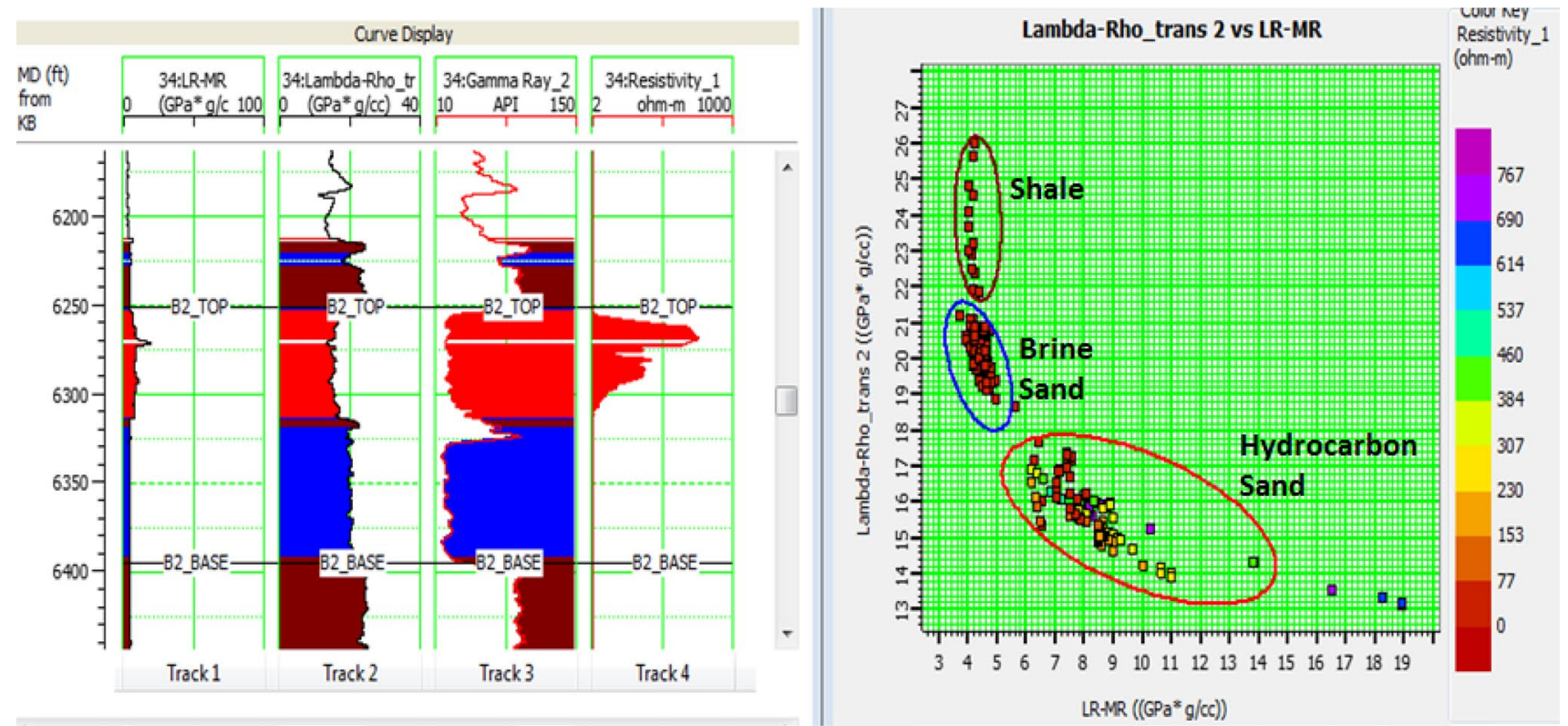

Fig. 7 Plot of Lambda-Rho versus Lambda-Rho/Mu-Rho for B2 reservoir showing a good separation between sand and shale and between brine and oil sand

under a normal condition. The cross-plot of both parameters in Fig. 8 indicates a very high value of Poisson ratio, a relatively higher value of P-impedance and a very low value of resistivity defining shale lithology. Sand is defined by a very low value of Poisson ratio and a relatively lower value of P-impedance. The hydrocarbon is characterized by a relatively lower value of P-impedance and an obviously lower value than the brine fill portion of the reservoir. Hence, Poisson ratio is a better discriminator for fluid than P-impedance.

\section{Seismic-based rock physics analysis}

Cross-section lines of derived rock attribute that cut across the exploited and prospective zone of our prospective
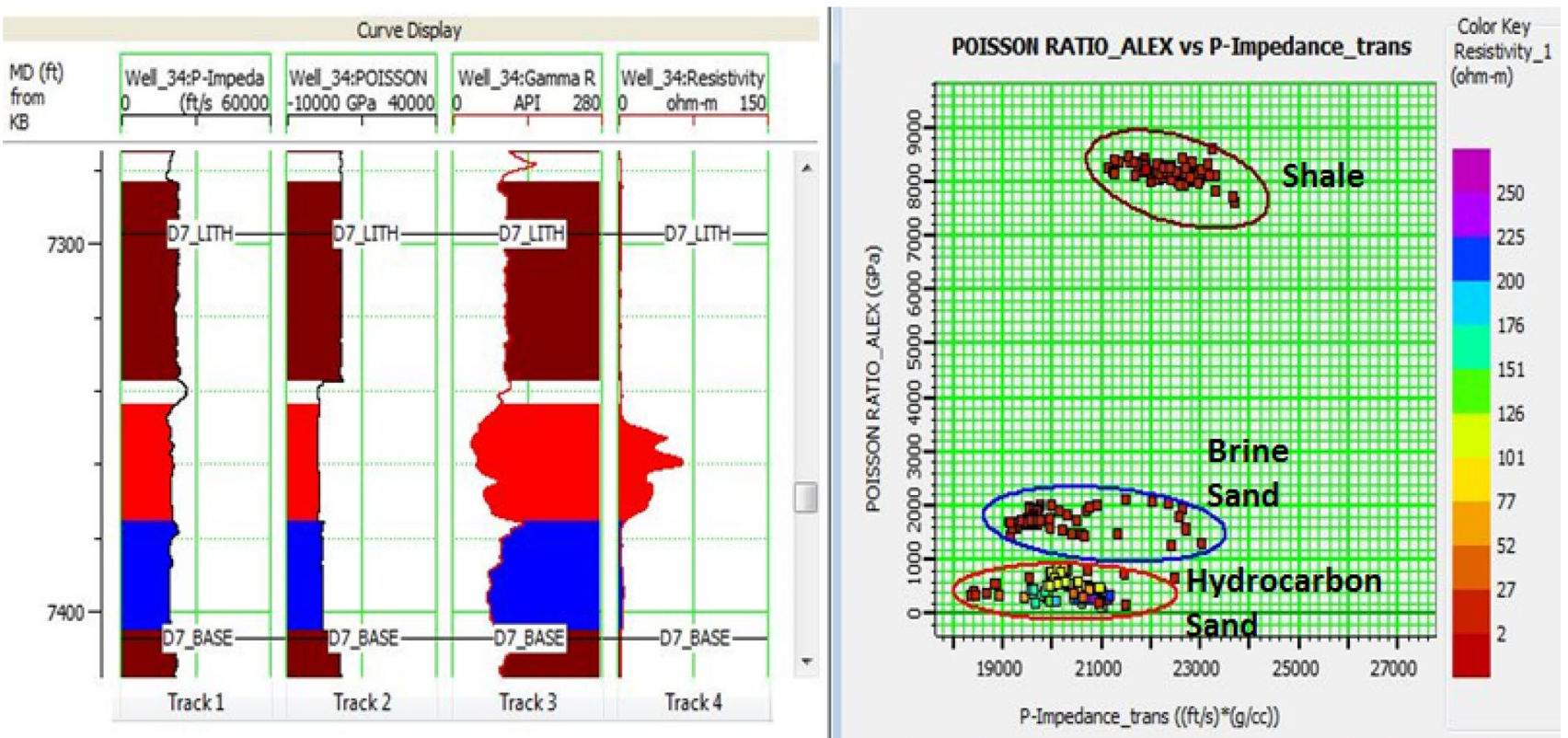

Fig. 8 Plot of Poisson ratio versus P-impedance Plot for D7 reservoir showing a good separation between sand and shale and between brine and oil sand 
reservoir were extracted from the model-based inversion result. This attributes were analyzed to verify the amplitude expression observed at the prospective zone of the field.

\section{Mu-Rho attribute cross-section analysis}

Mu-Rho was demonstrated to be a good lithology indicator. A cross section extracted from the inversion result is presented in Fig. 9. The Mu-rho log superimposed on the cross section along well 34 reveals a very good correlation with the extracted cross section, confirming that the inversion result was very good. From the legend and result of our well-based analysis, a very high value of Mu-Rho indicates the presence of sand. The superimposed gamma ray $\log$ confirms that the interval with high Mu-Rho value at the exploited zone corresponds to intervals with low gamma ray value indicating the presence of sand. This high Mu-Rho value was also observed in the prospective region below the reservoir top (red horizon), indicating the presence of good sands (Black ellipse).

\section{Lambda-Rho attributes cross-section}

The Lambda-Rho attribute is a fluid indicator and as demonstrated in the well-based cross-plot analysis, a low value indicates the presence of sand while a much more lower value indicates the presence of hydrocarbon-bearing sand, while high value respond corresponds to shale lithology. The Lambda-Rho cross section presented in Fig. 10 shows a good correlation between the well log and inversion-derived attribute, which agrees perfectly with the gamma ray log. In the exploited zone, low value of Lambda-Rho was observed between 7.5 and 5.0 Gpa for the reservoir intervals. The D2 reservoir has expression of the least Lambda-rho value within the reservoir interval indicative of the presence of hydrocarbon. It was observed that, of the two reservoirs observed on the exploited zone, only the D2 reservoir has such similar response at the prospective zone (within the black ellipse). This response could possibly be due to the hydrocarbon presence just like the amplitude map earlier indicated.

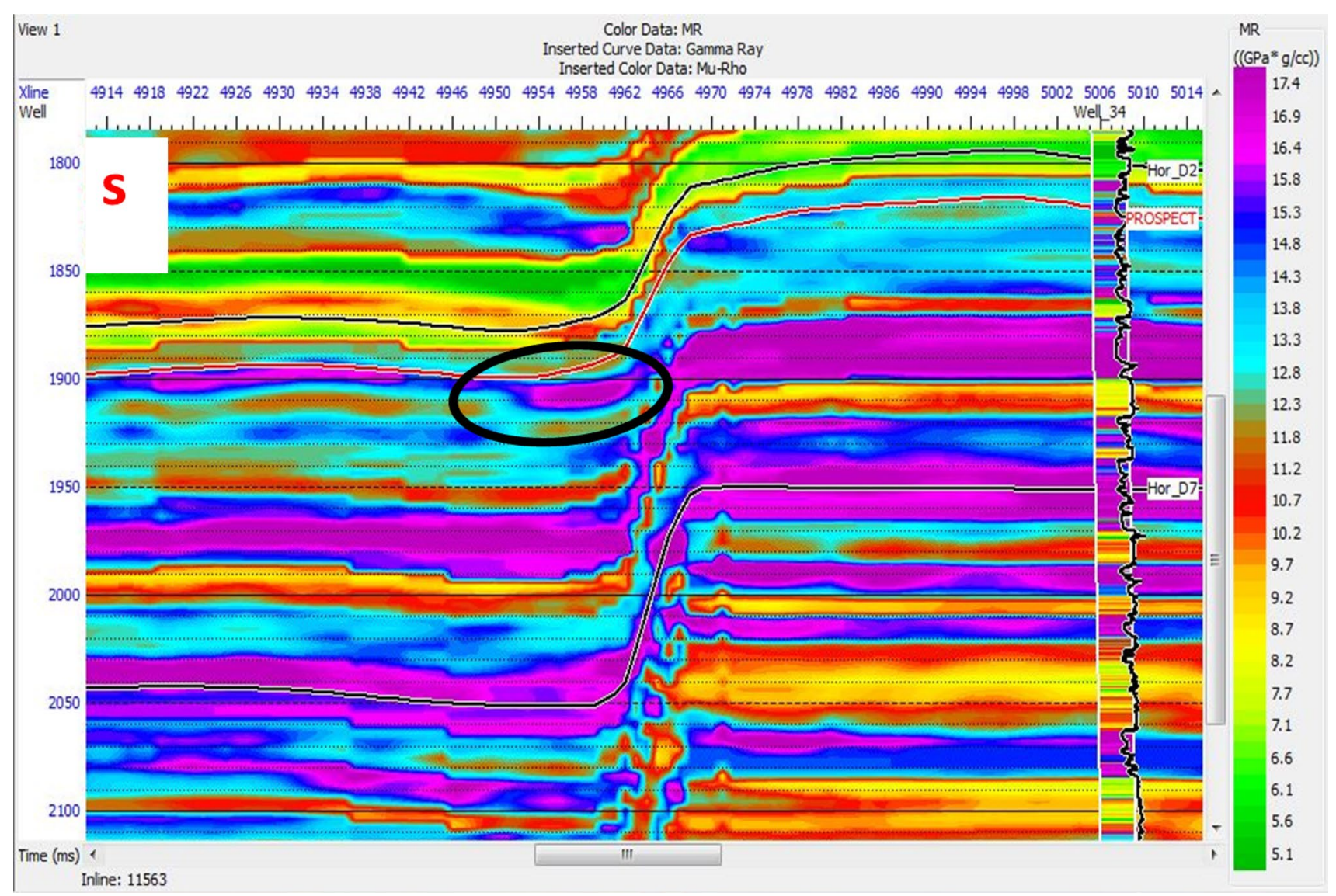

Fig. 9 Mu-Rho Rho attribute of inline 11,563 showing variation around the exploited and prospective zone 


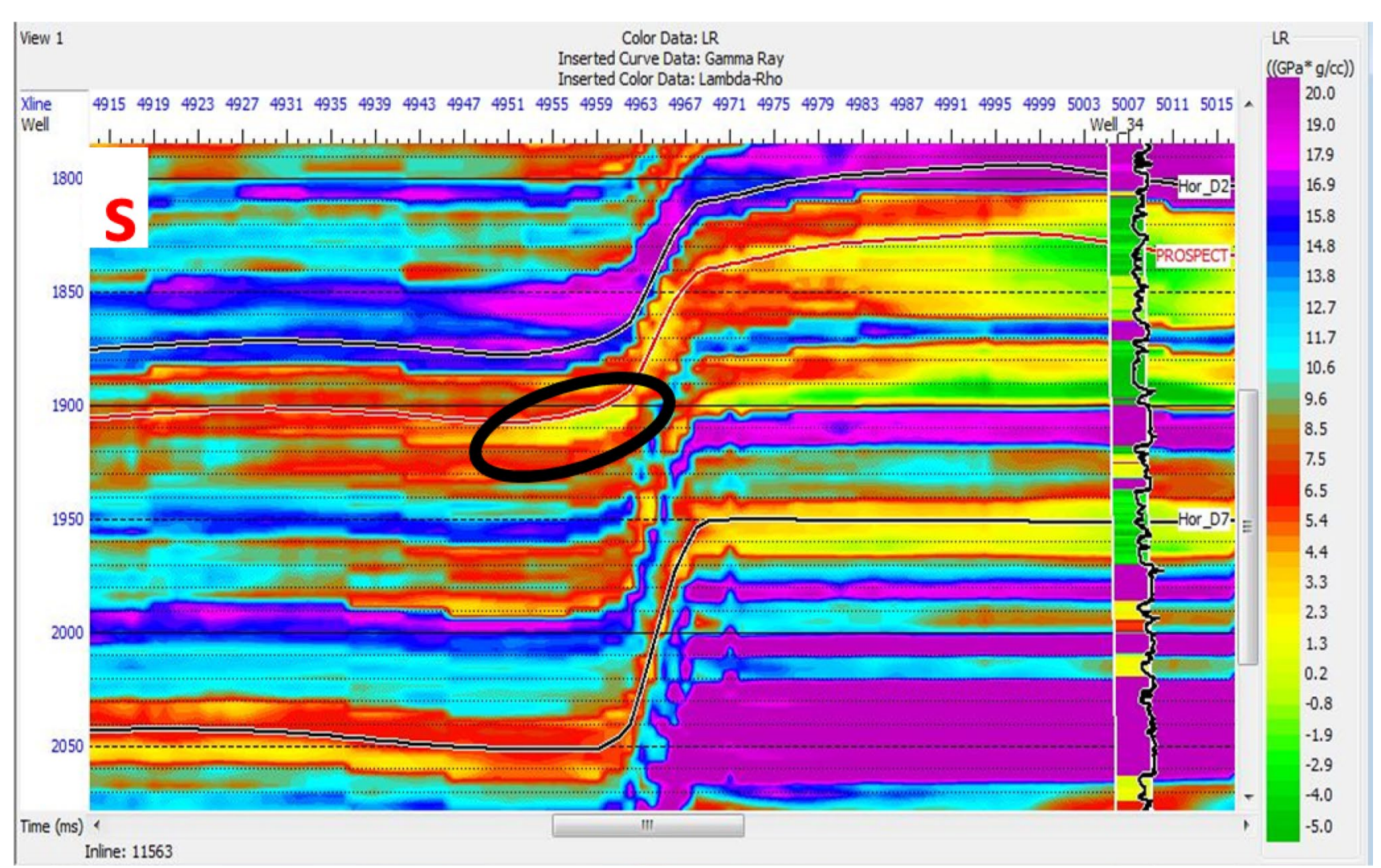

Fig. 10 Lambda Rho attribute of inline 11,563 showing variation around the exploited and prospective zone

\section{Seismic-based rock physics cross-plot analysis}

The D2 prospect identified from the amplitude and structural maps had been validated using several seismic-based rock physics attribute to increase our confidence that the observed response is as a result of the presence of hydrocarbon. To further increase certainty of the validated prospect, seismic-based cross-plot analysis was done using three attributes at a time to define zones that correspond to hydrocarbon presence.

Two of the cross-plot techniques that gave good result during well-based cross-plot analysis were adopted. They include Lambda-Rho versus Lambda-Rho/MuRho ratio, color coded with Poisson ratio and Mu-Rho versus Lambda-Rho color coded with Lambda-Rho/MuRho ratio. Attributes corresponding to the whole seismic cross-section panel were plotted in the cross-plot space. The region in the cross-plot space that best defines hydrocarbon-bearing sand responds was enclosed in the red ellipse, which was automatically posted at the appropriate zone with hydrocarbon response in the seismic crosssection panel.

\section{Lambda-Rho versus Lambda-Rho/Mu-Rho ratio, color coded with Poisson ratio}

Figure 11 presents a cross-plot of Lambda-Rho versus Lambda-Rho/Mu-Rho ratio color coded with Poisson ratio. A zone was defined with very low values for all three attributes that define a region where hydrocarbon-bearing sand will plot (Russel 2010). Inserting an ellipse around the zone automatically plot the points at the corresponding zone on the seismic cross-section window. It was observed that the plotted zone corresponds to the region defined by the inversion attributes as hydrocarbon bearing. Thus, this validates D2 prospect in the undrilled area.

\section{Mu-Rho versus Lambda-Rho color coded with Lambda-Rho/Mu-Rho ratio}

The seismic-based cross-plot of Mu-Rho versus LambdaRho attribute color coded with Lambda-Rho/Mu-Rho ratio presented in Fig. 12 defined a zone with very high values for Mu-Rho, very low values for Lambda-Rho and Lambda-Rho/Mu-Rho ratio attribute that corresponds to 

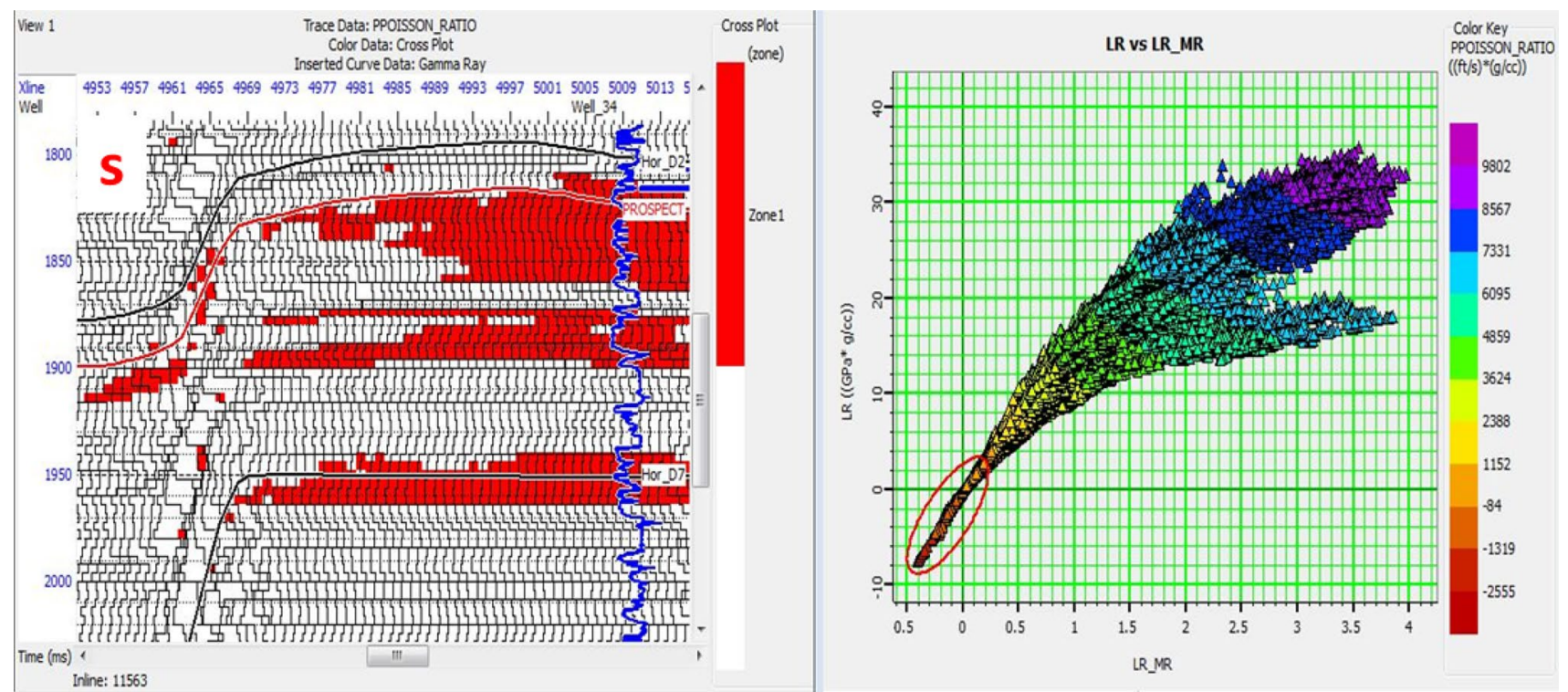

Fig. 11 Plot of Lambda-Rho versus Lambda-Rho/Mu-Rho ratio, color coded with Poisson ratio for Inline 11,563 confirming D2 reservoir to be hydrocarbon bearing in the prospective zone
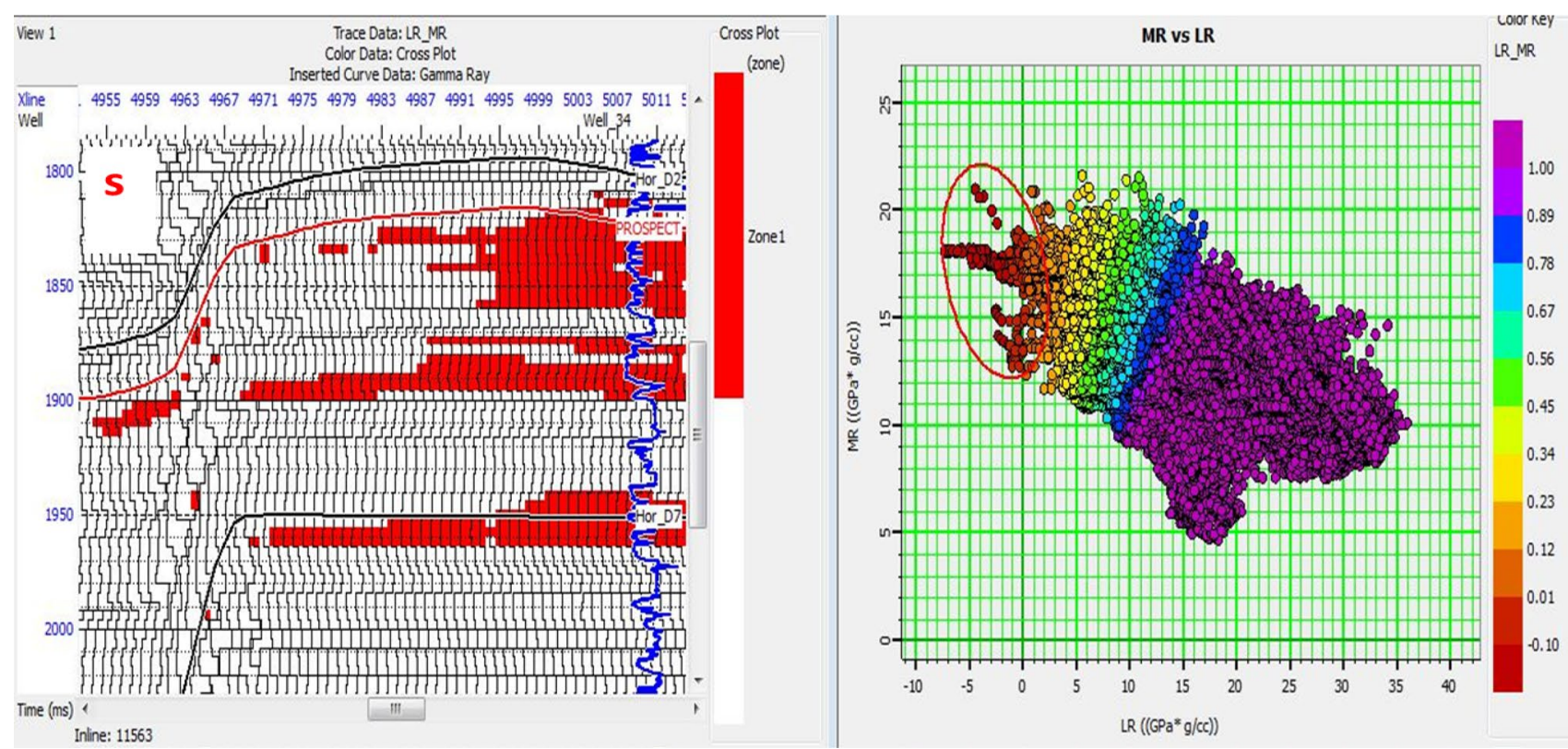

Fig. 12 Plot of Mu-Rho versus Lambda-Rho color coded with Lambda-Rho/Mu-Rho ratio for Inline 11,563 confirming D2 reservoir to be hydrocarbon bearing in the prospective zone

hydrocarbon-bearing region. The inserted ellipse also plotted the points to the corresponding zone on the crosssection panel similar to the result of Lambda-Rho versus Lambda-Rho/Mu-Rho ratio cross-plot in Fig. 11. We can therefore conclude hereby confirming that the response of the identified prospect was as a result of the presence of hydrocarbon.

\section{Conclusion}

Rock physics and cross-plot analysis were adopted to evaluate identified hydrocarbon prospect in the undrilled area of Eva field in the Niger Delta Basin. Structural and amplitude maps were initially used to identify the prospect 
by defining areas with structural highs and good amplitude support that conforms to structure at the prospective zone, similar to the hydrocarbon-bearing expressions at the exploited areas of the field. Well-based cross-plot feasibility analysis to select suitable rock attributes for seismic-based analysis presented Poisson ratio, LambdaRho and Lambda/Mu-Rho ratio as good fluid indicator and Mu-Rho as a viable lithology indicator. These selected parameters were adopted for both seismic-based rock physics and cross-plot analysis to evaluate the identified prospective zone, with attributes derived from modelbased inversion. Analysis of the results of rock attributes and cross-plot confirmed the identified prospect to be hydrocarbon bearing.

Acknowledgements Our sincere gratitude goes to Petroleum Trust Development Fund Nigeria, for awarding us the scholarship to Fund this research work. We also appreciate Shell Petroleum Development Company Nigeria, for releasing the data set used for this research. Special thanks go to the Center of Excellence in Geosciences and Petroleum Engineering for making their workstations and software available to complete this work.

Authors' contributions The manuscript is a product of a research work carried out by the first author; Dr. A. Ogbamikhumi, with some technical and non-technical contributions from the second author; Mr. N. S. Igbinigie.

Availability of data That the manuscript is an original work conducted by the author's, under close supervision which restrict data transferability by Shell Petroleum Development Company (SPDC) Nigeria.

\section{Compliance with ethical standards}

Conflict of interest I write to attest on behalf of the authors of the submitted manuscript titled 'Rock Physics Attribute Analysis for Hydrocarbon Prospectivity in the Eva Field Onshore Niger Delta Basin.' The article has not been published in any form neither is it currently under review with any other journal.

Code availability Petrel interpretation software and Hampson Rusell Suites were made available in the workstation of Center of Excellence in Geosciences and Petroleum Engineering, University of Benin, Nigeria.

Open Access This article is licensed under a Creative Commons Attribution 4.0 International License, which permits use, sharing, adaptation, distribution and reproduction in any medium or format, as long as you give appropriate credit to the original author(s) and the source, provide a link to the Creative Commons licence, and indicate if changes were made. The images or other third party material in this article are included in the article's Creative Commons licence, unless indicated otherwise in a credit line to the material. If material is not included in the article's Creative Commons licence and your intended use is not permitted by statutory regulation or exceeds the permitted use, you will need to obtain permission directly from the copyright holder. To view a copy of this licence, visit http://creativecommons.org/licenses/by/4.0/.

\section{References}

Abdel-Fattah MI, Pigott JD, El-Sadek MS (2020) Integrated seismic attributes and stochastic inversion for reservoir characterization: insights from Wadi field (NE Abu-Gharadig Basin, Egypt). J Afr Earth Sci 161:103661

Adeoti L, Adesanya OY, Oyedele KF, Afinotan IP, Adekanle A (2018) Lithology and fluid prediction from simultaneous seismic inversion over Sandfish field, Niger Delta, Nigeria. Geosci J 22:155-169

Adojoh O, Fabienne M, Duller R, Osterloff P (2017) Tropical palaeovegetation dynamics, environmental and climate change impact from the low latitude Coastal Margin, Niger Delta, Gulf of Guinea during the Late Quaternary. J Paleoecol Afr 35:107-144

Asquith G, Gibson C (1982) Basic well-log analysis for geologist: AAPG, Tulsa Oklahoma. AAPG Series, vol 3, pp 41-100

Avbovbo AA (1978) Tertiary lithostratigraphy of Niger Delta. Am Assoc Pet Geol Bull 62:295-300

Avseth P, Mukerji T, Mavko G (2008) Quantitative seismic interpretation: applying rock physics tool to reduce interpretation risk. Cambridge University Press, Cambridge

Bosch M, Campos C, Fernandez E (2009) Seismic inversion using a geostatistical, petrophysical, and acoustic model. Lead Edge 2009:690-696

Brown AR (1987) The value of seismic amplitude. Lead Edge 10:30-33

Castagna JP, Swan HW (1997) Principle of AVO crossploting. Lead Edge 12:337-343

Dewar J, Pickford S (2001) Rock physics for the rest of us- - an informal discussion. Can Soc Explor Geophys Rec 26(5):42-49

Doust H, Omatsola E (1990) Niger Delta. In: Edwards JD, Santogrossi PA (eds) Divergent/passive Margin Basins, vol 48. American Association of Petroleum Geologists, Tulsa, pp 239-248

Gassmann F (1951) Uber die elastizitat poroser medien: Vier. der Naturforsch. Gesellschaft 96:1-23

Goodway W, Chen T, Downton J (1997) Improved AVO fluid detection and lithology discrimination using lame petrophysical parameters. The Society of Exploration Geophysicists. In: 67th annual international meeting, Denver

Han DH, Yao Q, Zhao HZ (2007) Complex properties of heavy oil sand. In: SEG, expanded abstracts, vol 77, pp 1609-1613

Krebs JR, Anderson JE, Hinkley D, Neelamani R, Lee S, Baumstein A, Lacasse MD (2009) Fast full-wave field seismic inversion using encoded sources. Geophysics 74(6):177-188

Kulke H (1995) Nigeria. In: Kulke H (ed) Regional petroleum geology of the world part II Africa, America, Australia and Antarctica. Gebrüder Borntraeger, Berlin

Li Y (2004) Lithology and partial gas saturation. CSEG National Convention 2004, p S054

Ogararue DO, Anine DO (2016) An integration of rock physics, AVO modelling and analysis for reservoir fluid and lithology discrimination in a Niger Delta deep water block. IOSR J Appl Geol Geophys $4: 36-46$

Ogbamikhumi A, Tralagba T, Osagiede EE (2017) Time-lapse seismic monitoring of onshore reservoirs in Niger Delta, field ' $\mathrm{K}$ ' as a case study. Niger J Environ Sci Technol 1:23-27

Ogbamikhumi A, Salami SA, Igbinigie NS (2019) Shear wave estimation for rock physics reservoir evaluation of Jay field in the Niger Delta Basin. J Niger Assoc Math Phys 49(1):193-198

Omudu LM, Ebeniro JO (2005) Cross plot of rock properties for fluid discrimination, using well data in offshore Niger Delta. Niger J Phys 17:16-20

Pickett G (1963) Acoustic character logs and their applications in formation evaluation. J Pet Technol 15:650-667

Reijers TJA, Petters SW, Nwajide CS (1996) The Niger Delta Basin: SPDC corporate reprographic services, Warri, Nigeria

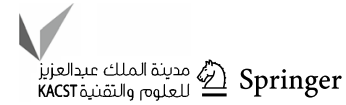


Russel B (2010) Making sense of all that AVO and inversion stuff!. The Milton Dobrin Lecture series. April, 2010, pp 1-57

Short KC, Stauble AJ (1967) Outline of geology of Niger Delta. AAPG Bull 51:764-772

Smith TM, Sondergeld CH, Rai CS (2003) Gassmann fluid substitutions: a tutorial. Geophysics 68:430-440

Toshev M (2017) Study of the capabilities of AVO-methods for the detection of hydrocarbon accumulations. J Min Geol Sci 60:94-98

Ujuanbi O, Okolie J, Jegede SI (2008) Lambda-mu-rho technique as a viable tool for litho-fluid discrimination - the Niger Delta example. Int J Phys Sci 2(7):173-176
Whiteman A (1982) Nigeria: its petroleum geology, resources and potential: Graham and Trotman Ltd., vol 1, pp 114-131

Publisher's Note Springer Nature remains neutral with regard to jurisdictional claims in published maps and institutional affiliations. 